\title{
DESCRIPTION OF A NEW SPECIES OF SIMULIUM (SIMULIUM) FROM HOKKAIDO, JAPAN (DIPTERA: SIMULIIDAE)
}

\author{
HIROYUKI TAKAOKA' ${ }^{1}$ and KATSUMI SAITO ${ }^{2}$ \\ Accepted September, 10, 2002
}

\begin{abstract}
A new black-fly species, Simulium nemuroense sp. nov., is described from pharate female, pharate male, pupal and larval specimens collected from Hokkaido, Japan. This new species is assigned to the slossonae speciesgroup within the subgenus Simulium (Simulium), by having the following characters: in both sexes of adults, no hairs on the basal portion of radial vein; in the female, the claw with a large basal tooth and the genital fork with two projections on each arm, one directed anteriorly and the other posteromedially; in the male, the ventral plate lamellate with a median wide projection, the style longer than the coxite and with a prominent basal protuberance; and in the larva, the postgenal cleft very deep and the presence of the ventral papillae. S. nemuroense sp. nov. is easily distinguished from all the three known species by several characters including the male genitalia with a wide ventral plate and a hairy basal protuberance of the style, and the cocoon with an anterodorsal projection. This is the first record of the slossonae species-group in Japan.
\end{abstract}

Key words: Simuliidae, Simulium, black-fly, Diptera, Japan, new species

Recently, one of us (KS) found a new black-fly species while collecting simuliid pupae and larvae for faunal and ecological studies in Hokkaido, Japan. This species is assigned to the slossonae species-group within the subgenus Simulium (Simulium), recently created by Currie (1997), which includes only three known species found in Holarctic Region (Crosskey, 1999), all having been previously placed in the subgenus Simulium (Parabyssodon) by Crosskey and Howard (1997).

This new species is here described from the pharate females and pharate males, pupae and mature larvae. It should be noted that some adult body parts, such as head, thorax and legs, were not fully developed in coloration, making their descriptions incomplete. The morphological features and terms used herein follow mostly those of Crosskey (1969), and partially those of Takaoka (1983).

\section{Simulium (Simulium) nemuroense sp. nov.}

DESCRIPTION. Female. Body length $3.5 \mathrm{~mm}$. Head. Narrower than thorax. Frons dark, shiny, with several dark hairs in vertical row along each lateral margin; frontal ratio 1.4:1.0:1.4. Frons-head ratio 1.0:4.2. Clypeus dark, shiny, moderately covered with dark hairs laterally but widely bare on median longitudinal area. Fronto-ocular area (Fig. 1) well developed, triangular. Proboscis $0.64 \times$ as long as clypeus. Antenna composed of 2+9 segments. Maxillary palp (Fig. 2) consisting of 5 segments, proportional lengths of 3rd, 4th and 5th segments 1.0:1.1:2.4; 3rd segment not enlarged, thinner than 4th segment, with sensory vesicle of variable shapes and sizes: sensory vesicle ellipsoidal, $1.7 \times$ as long as wide and ca. $0.3 \times$ as long as 3 rd segment in the holotype female (Fig. 3), while much elongated, $2.9 \times$ as long as wide and ca. $0.4 \times$ as long as 3 rd segment in the paratype female (Fig. 4). Maxillary lacinia with 10 or 11 inner and 13 or 14 outer teeth. Mandible with ca. 26 inner and 8 outer teeth. Cibarium (Fig. 5) smooth on posterior margin, with cornuae directed upwards. Thorax. Scutum shiny, with slightly darker portion along each lateral margin and on prescutellar area, densely covered with recumbent scale-like hairs. Scutellum with many hairs. Postscutellum bare. Pleural membrane bare. Katepisternum longer than deep and bare. Legs. Foreleg: at least apical caps of femur and tibia, and whole of tarsus darkened; basitarsus much dilated, ca. $4.6 \times$ as long as its greatest width. Midleg: at least coxa, apical caps of femur and tibia, apical $1 / 2$ of basitarsus, and whole of remaining tarsal segments dark. Hind leg: at least coxa, apical caps of femur, tibia and basitarsus, and most of remaining tarsal segments dark; basitarsus (Fig. 6) parallel-sided; calcipala well developed, nearly as long as wide; pedisulcus well developed. Claws (Fig. 7) each with large basal tooth $0.5 \times$ as long as claw. All femora and mid

1 Department of Infectious Diseases (formerly Infectious Disease Control), and Research Center for Asian and Caribbean Diseases, Oita Medical University, Hasama, Oita 879-5593, Japan

2 Department of Parasitology, School of Medicine, Yokohama City University, Kanazawa-ku, Yokohama City, Kanagawa 236-0004, Japan 
and hind tibiae covered with broad scale-like hairs as well as simple hairs (Fig. 8). Wing. Costa with 2 parallel rows of short spines as well as hairs. Subcosta bare. Basal portion of radius bare. Basal cell absent. Abdomen. Basal scale light brown, with fringe of pale long hairs. Dorsal surface of segment 2 pale, with pair of large shiny spots on anterior $1 / 2$, medium brown on posterior $1 / 2$; that of remaining segments medium brown, sparsely covered with short hairs; terga of segments 6-8 shiny when illuminated; ventral surface of segment 7 with large sternal plate medially. Genitalia (Figs. $9 \& 10$ ). Sternum 8 wide, bare medially but furnished with 5 or 6 long hairs as well as a few short setae on each side. Anterior gonapophysis triangular, thin, membraneous except inner margin narrowly sclerotized, densely covered with microsetae, interspersed with 3-5 short setae. Genital fork of inverted Y-form, with slender, well-sclerotized stem and wide arms; each arm with large lobe-like projection directed posteromedially and
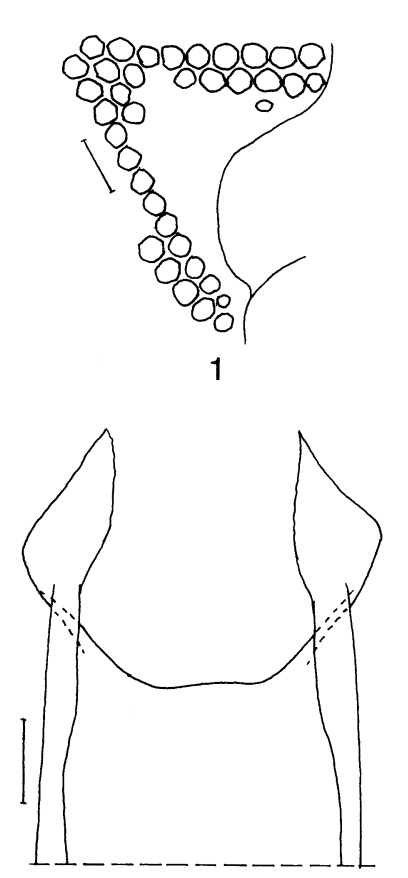

5

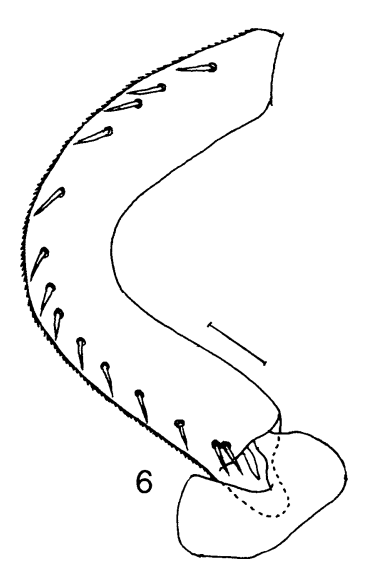

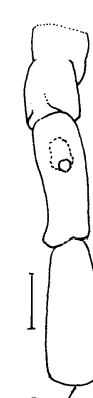
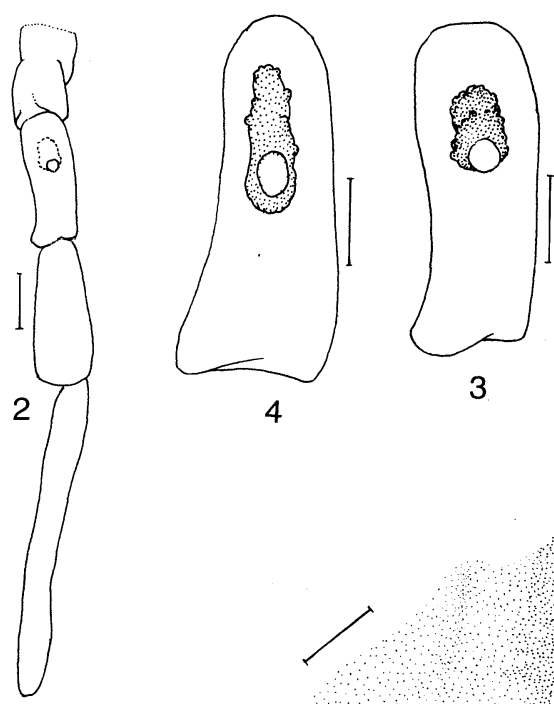
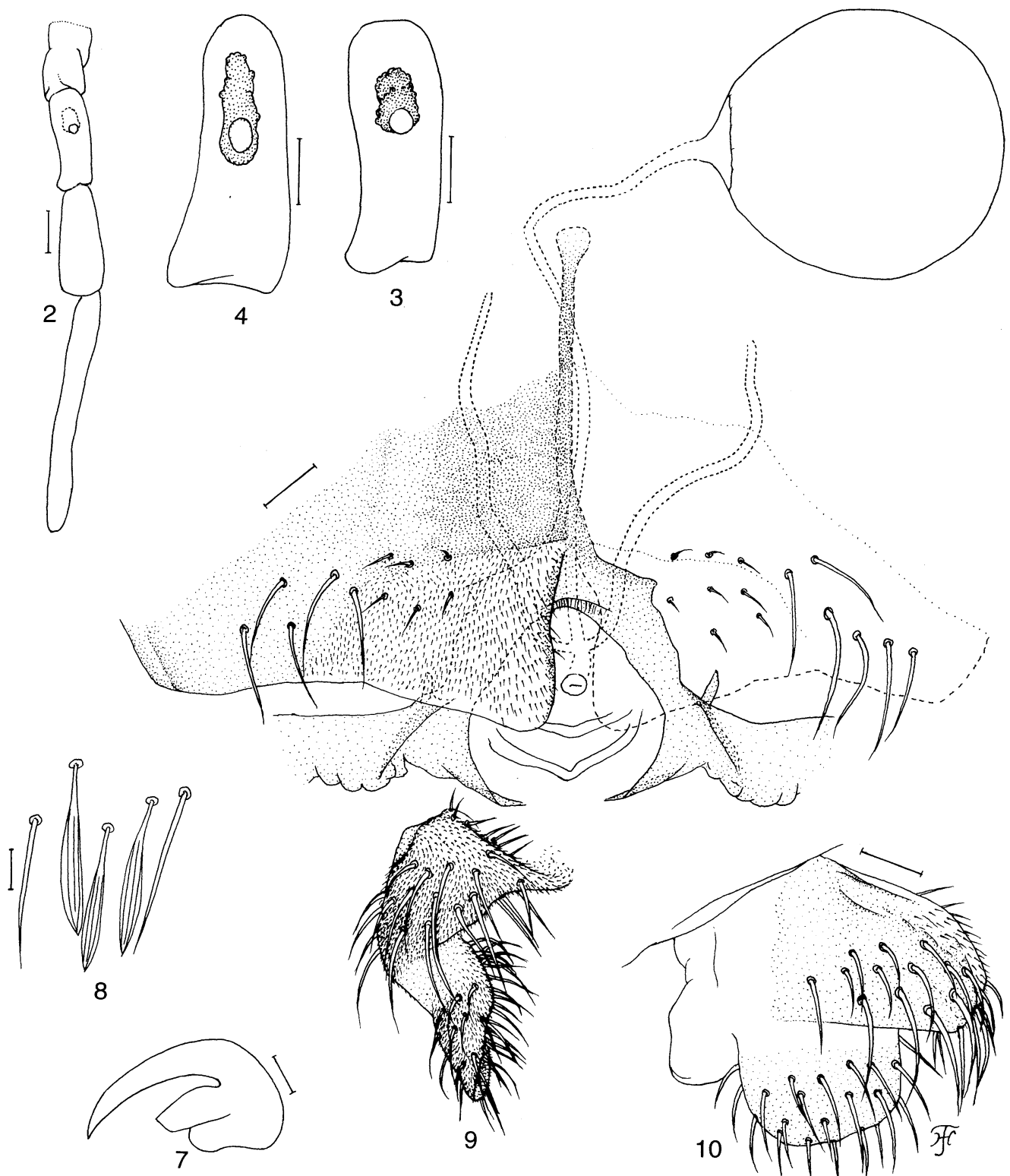

Figures 1-10. Female characters of Simulium nemuroense sp. nov. 1, fronto-ocular area; 2, maxillary palp; 3 \& 4, 3rd segments of maxillary palp with sensory vesicle; 5 , cibarium; 6 , hind basitarsus and 2 nd tarsal segment; 7 , claw; 8 , simple and scale-like hairs on outer surface of hind tibia; 9, genitalia in situ (ventral view), showing 8th sternum, anterior gonapophyses, genital fork, spermatheca with main and accessory ducts, and right paraproct and cercus; 10 , right paraproct and cercus (lateral view). Scale bars $0.01 \mathrm{~mm}$ for figs. $7 \& 8 ; 0.03 \mathrm{~mm}$ for figs. 1, 3-5, $9 \& 10 ; 0.05 \mathrm{~mm}$ for figs. $2 \& 6$. 
small slender projection directed forward. Paraproct of usual form, somewhat protruding ventrally. Cercus in lateral view rounded posteriorly, ca. $0.5 \times$ as long as wide. Spermatheca globular, strongly sclerotized except small area around juncture to duct, and duct itself unsclerotized, with distinct reticulate surface pattern, and with numerous internal setae; main spermathecal duct narrow, while both accessory ducts slightly wider than main duct and with tapered apex.

Male. Body length $3.5 \mathrm{~mm}$. Head. Slightly wider than thorax and holoptic. Upper eye consisting of large facets in 27 vertical columns and 25 horizontal rows. Clypeus dark, shiny, widely bare medially, but moderately covered with hairs along lateral margins. Antenna composed of $2+9$ segments, dark brown except base of 1st flagellar segment pale; 1st flagellar segment somewhat elongate, ca. $1.4 \times$ as long as 2nd flagellar segment. Maxillary palp composed of 5 segments, brown, proportional lengths of 3rd, 4th and 5th segments 1.0:1.2:2.5; 3rd segment (Fig. 11) of moderate size; sensory vesicle small, ellipsoidal, ca. $0.2 \times$ as long as 3rd segment. Thorax. Scutum dark brown, with silvery
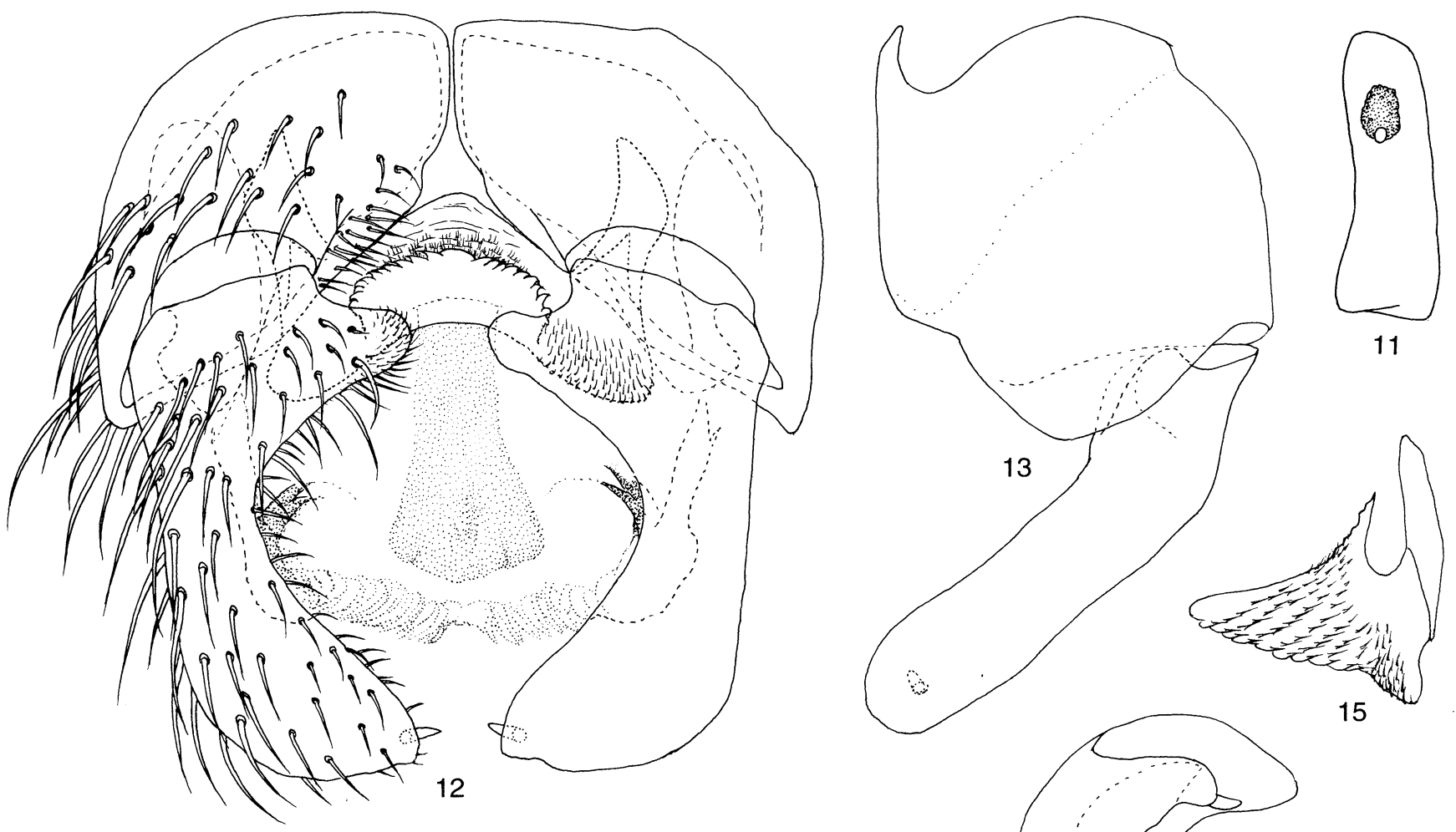

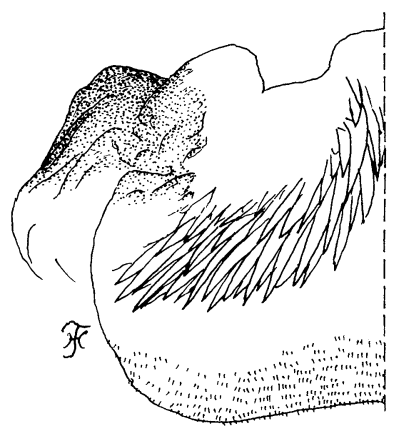

17

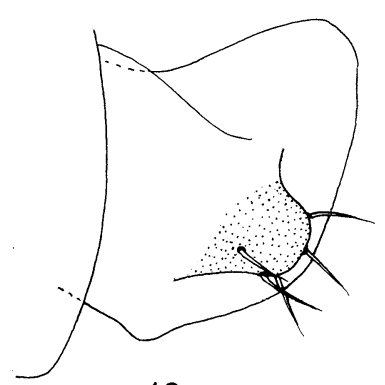

19

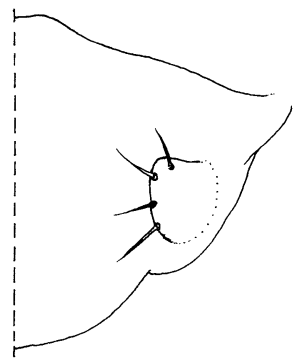

18

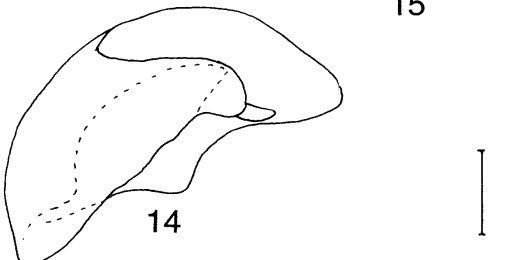

Figures 11-19. Male characters of Simulium nemuroense sp. nov. 11, 3rd segment of maxillary palp with sensory vesicle; 12, genitalia in situ (ventral view), showing coxites, styles, ventral plate, parameres and median sclerite; 13, right coxite and style (lateral view); 14, right style (end view); 15 \& 16, ventral plates (15, lateral view; 16, end view); 17, right paramere and aedeagal membrane (end view); 18 \& 19, posterior tips of abdomen showing cercus (18, end view; 19 , lateral view). Scale bar $0.03 \mathrm{~mm}$ for all figures. 
shiny marking consisting of pair of narrow crescent-shaped spots each directed from anterolateral corner toward posteromedially on each shoulder, narrow band along each lateral margin, and large spot on prescutellar area, all connected to one another, densely covered with recumbent fine hairs, and with several longer hairs on prescutellar area. Scutellum dark, with many hairs. Postscutellum dark and bare. Pleural membrane bare. Katepisternum medium brown, longer than deep, and bare. Legs. Foreleg: coxa yellow except inside surface light brown; trochanter medium brown; femur dark yellow with apical cap medium brown; tibia pale except apical cap and inner surface of basal $1 / 4$ or $1 / 3$ medium brown; outer surface largely white shiny; tarsus medium brown; basitarsus slender, moderately dilated, ca. $4.8 \times$ as long as its greatest width. Midleg: coxa and trochanter medium brown; femur dark yellow or light brown with apical cap medium brown; tibia light brown with base yellow and apical cap medium brown; tarsus light to medium brown. Hind leg: coxa medium brown; trochanter dark yellow; femur dark yellow or light brown, with apical cap medium brown; tibia light to medium brown with base dark yellow and apical cap dark brown; basitarsus dark yellow with apical 1/4 medium brown, other tarsal segments light brown; basitarsus slender, parallel-sided, much narrower than hind tibia and femur, as in female. Calcipala well developed, nearly as long as wide; pedisulcus well developed. All femora and mid and hind tibiae covered with broad scale-like hairs as well as simple hairs, as in female. Wing. As in female. Abdomen. Basal scale light brown, with fringe of dark long hairs. Dorsal surface of segment 2 pale on anterior $1 / 2$ with pair of shiny spots, medium brown on posterior $1 / 2$; that of other segments medium to dark brown, with dark simple hairs; segments 5-7 each with paired shiny dorsolateral spots. Genitalia (Figs. 12-19). Coxite large, cylindrical. Style elongate, ca. $1.2 \times$ as long as coxite, flattened dorsoventrally, narrowed from base to middle, then widened apically, with apical spine; style with prominent hairy basal protuberance with rounded apex directed medially. Ventral plate in ventral view lamellate, much shorter than wide, with its lateral and posterior margins widely depressed, and anterior margin convex, moderately covered with setae on ventral surface except most of anterior portion bare, with stout arms somewhat diverged, and prominent plate-like median projection along posterior margin; anterior surface of this median projection moderately and elaborately covered with spinous setae but posterior surface with no setae; lateral margins of this median projection appearing toothed when viewed from end. Paramere of normal form, with numerous hooks. Median sclerite simple, plate-like, slightly widened toward apex. Aedeagal membrane densely covered with spinous microse- tae. Ventral surface of 10th abdominal segment bare. Cercus small, rounded in lateral view, and with 4 or 5 simple hairs.

Pupa. Body length $3.2-3.6 \mathrm{~mm}$. Head. Integument yellow, moderately covered with small round tubercles; frons with 3 simple (or rarely bifid) medium-long trichomes on each side, of which 2 trichomes situated close together but the dorsalmost trichome separated at some distance from the others, while face with 1 simple medium-long trichome on each side. Thorax. Integument yellow, moderately covered with small round tubercles, with 3 simple long trichomes mediodorsally, 2 simple long trichomes mediolaterally, 1 simple medium-long trichome posterolaterally, and 3 simple medium-long trichomes ventrolaterally, on each side. Gill either with 6 long slender filaments arranged in 3 pairs (Fig. 20), as in 24 of 32 pupae and pupal exuviae examined, or with 4 long slender filaments arranged in 2 pairs (Fig. 21), as in remaining 8 pupae; in both cases, gill divided basally into 2 (dorsal pair and ventrolateral one) basally, then each divided again into 2 filaments (dorsal and ventral filaments) from very short stalk (Figs. 20 \& 21); in case of 6 filaments (Fig. 22), each filament of ventrolateral pair divided further into 2 filaments from moderate to very long secondary stalk, i.e., out of 24 pupae, 14 with all 4 secondary stalks ( 2 each on left and right side) of moderate length, 8 with all long or very long secondary stalks (bifurcation occurring near apical tip of filaments in 3 pupae), and 1 with 3 long secondary stalks and 1 moderate one, and 1 with 2 long secondary stalks and 2 moderate ones; ventral filament of dorsal pair 3.5-4.1 mm long, subequal to or a little longer than pupal body, usually slightly longer and thicker than others (1.2-1.4 $\times$ as long as shortest filament, which is $2.5-3.6 \mathrm{~mm}$ long); all filaments pale, generally directed forward; their cuticular surface with distinct sharp annular ridges and furrows (though ridges becoming indistinct near apex), and densely covered with minute tubercles. Abdomen. Terga 1 and 2 yellowish, bare; tergum 1 with 1 simple slender medium-long seta on each side; tergum 2 with 1 simple slender medium-long seta and 5 short spinous setae on each side; terga 3 and 4 each with 4 hooks and a few spinous setae on each side; tergum 5 bare; terga 6-9 each with transverse row of spine-combs directed backward on each side; tergum 9 with pair of distinct conical terminal hooks (Fig. 23). Sternum 4 with 1 bifid hook (subequal in size to those on sterna 5-7), 1 simple hooklet and a few slender setae on each side; sternum 5 with pair of bifid hooks and a few slender setae on each side; sterna 6 and 7 each with 1 bifid hook submedially and 1 simple hook laterally and a few slender setae on each side; each side of last segment with 2 simple slender setae but no grapnel-shaped 
hooklets. Cocoon (Figs. 24 \& 25). Simple, wall-pocketshaped, moderately woven without open spaces or windows in web, with anterodorsal projection of short or moderate lengths; individual threads generally visible; $3.8-5.0 \mathrm{~mm}$ long $\times 1.7-2.2 \mathrm{~mm}$ wide.

Mature larva. Body length 5.0-6.0 mm. Body creamy white, somewhat light brownish on dorsal surface of abdominal segments 5-8 in some larvae (there is a possibility that color markings on the larval body were probably faded out since the larvae had been long preserved in ethanol solution); in dorsal view, thoracic segments somewhat swollen like a barrel, abdominal segments 1-4 somewhat narrower than thorax, with moderate intersegmental constrictions, and segments 5-9 swollen also like a barrel, with widest portion on segment 6; in lateral view, larval body markedly arched dorsally (Photo. 1). Cephalic apotome (Photo. 2) pale, with distinct positive head spots; eye brow faintly positive; 2 large spots posterior to eye-spot region distinctly positive; isolated spots below eye-spot region indistinct. Cervical sclerites composed of 2 small rod-like pieces, not fused to occiput, widely separated medially from each other. Antenna (Fig. 26) consisting of 3 segments and apical sensillum, slightly shorter than stem of labral fan;

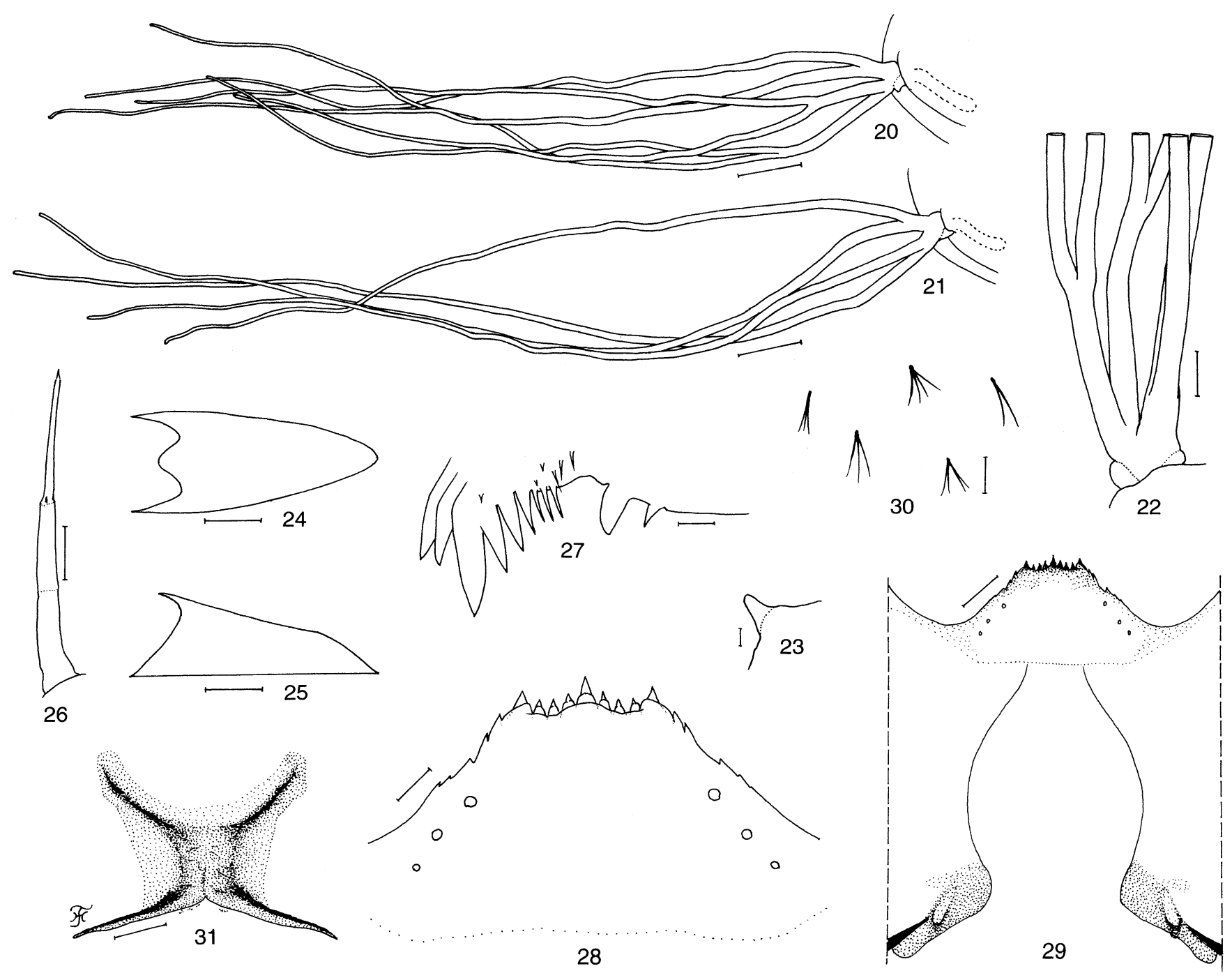

Figures 20-27. Pupal and larval characters of Simulium nemuroense sp. nov. 20-25, pupa; 26-31, larva. 20, gill with 6 filaments (lateral view); 21, gill with 4 filaments (lateral view); 22, basal portion of left gill with 6 filaments (dorsal view); 23, terminal hook (lateral view); 24 \& 25, cocoons (24, dorsal view; 25, lateral view); 26, left antenna (dorsal view); 27 , apex of mandible; 28 , hypostomium; 29 , head capsule (ventral view) showing hypostomium and postgenal cleft. Scale bars $0.01 \mathrm{~mm}$ for figs. $23,27 \& 30 ; 0.02 \mathrm{~mm}$ for fig. $28 ; 0.05 \mathrm{~mm}$ for figs. $26,29 \& 31 ; 0.1 \mathrm{~mm}$ for fig. 22; $0.3 \mathrm{~mm}$ for figs. $20 \& 21 ; 1.0 \mathrm{~mm}$ for figs. $24 \& 25$. 

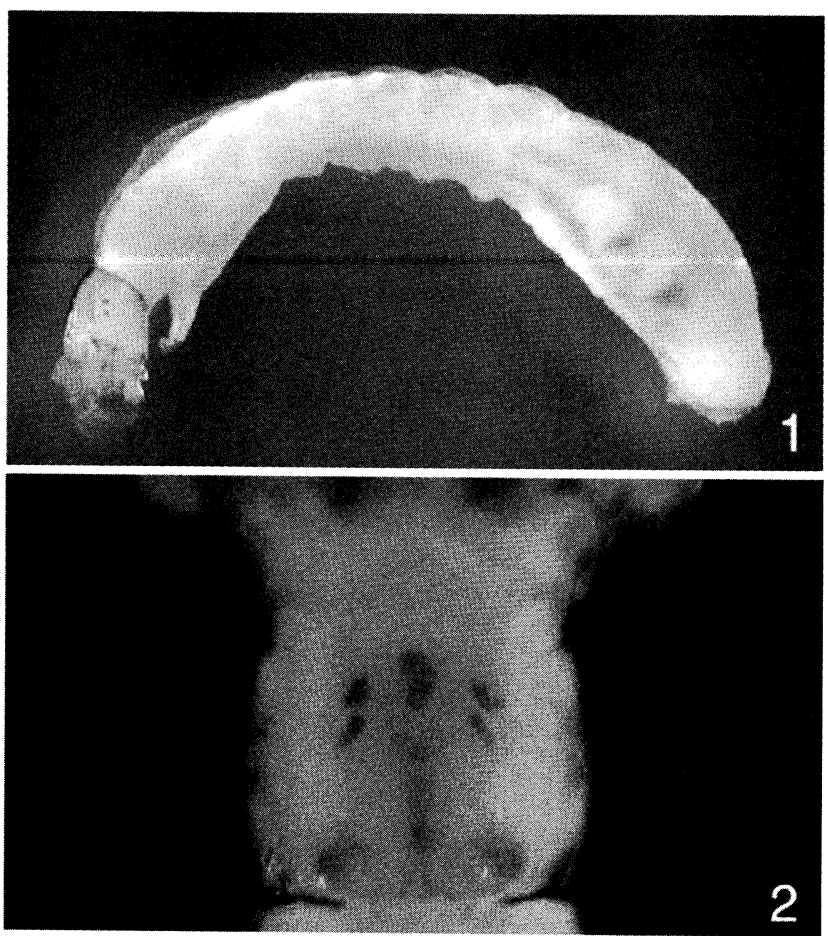

Photos. 1 and 2. Larva of Simulium nemuroense sp. nov. 1, whole body of mature larva (lateral view); 2 , head showing positive head spots on clypeus (dorsal view).

proportional lengths of 1st, 2nd and 3rd segments 1.0:1.0: 1.3. Labral fan with ca. 30 main rays. Mandible (Fig. 27) with 2 usual mandibular serrations; comb-teeth composed of 3 teeth, decreasing in length from 1st to 3rd; supernumerary serrations absent. Hypostomium (Fig. 28) with anterior row of 9 teeth; median and corner teeth well developed; 3 intermediate teeth on each side also sharply pointed; lateral serrations moderately developed; 3 hypostomal bristles lying subparallel to lateral margin on each side. Postgenal cleft (Fig. 29) deep, reaching posterior margin of hypostomium. Thoracic and abdominal cuticle sparsely covered with dark minute spines with 0-4 branches (Fig. 30) dorsally and dorsolaterally; last segment also covered with colorless short setae on each side of anal sclerite; cluster of minute spines around anus absent. Rectal papilla of 3 lobes each with 6 or 7 finger-like secondary lobules. Anal sclerite (Fig. 31) of usual X-form, with posterior arms nearly as long as anterior ones; basal portion of arms widely sclerotized. Accessory sclerite absent. Ventral papillae (Photo. 1) moderately developed, conical and placed ventrally, then, well discernible even when the larva is viewed laterally. Posterior circlet with 56-60 rows of up to 13 hooklets per row.

TYPE SPECIMENS. Holotype female, dissected out of a pupa, collected from the Nishimarubetsu River, just below the Barasan Bridge, Bekkai Town, Notsuke County, Nemuro District, eastern Hokkaido, Japan, 23. VII. 1998, by K. Saito and A. Kanayama. Paratypes, 1 pharate female, 4 pharate males, 13 pupae, 19 pupal exuviae, 14 mature larvae, same data as holotype. Holotype and most of paratype specimens will be deposited at the Natural History Museum, London, UK.

BIOLOGICAL NOTES. The immature stages of $S$. nemuroense sp. nov. occur in a small, somewhat muddy stream (2-3 m wide, ca. $0.5 \mathrm{~m}$ deep, and exposed to the sun), very slowly flowing in the marshy area (ca. $6 \mathrm{~m}$ in altitude) near the coast of the Nemuro Bay. They were found on the surface of grass leaves trailing in the water. This species was collected together with $S$. yonagoense Okamoto, 1958.

DISTRIBUTION. Limited to the type locality in Nemuro, Hokkaido, Japan.

ETYMOLOGY. The species nemuroense is named after the district name, Nemuro, where this species was collected.

REMARKS. This new species is assigned to the slossonae species-group within the subgenus Simulium (Simulium), by having the following characters: in both sexes of adults, no hairs on the basal portion of radial vein; in the female, the claw with a large basal tooth (Fig. 7) and the genital fork with two projections on each arm, one directed anteriorly and the other posteromedially (Fig. 9); in the male, the ventral plate lamellate with a wide median projection and the style with a prominent basal protuberance (Fig. 12); and in the larva, the postgenal cleft very deep (Fig. 29) and the presence of the ventral papillae (Photo. 1). This is the first record of the slossonae species-group in Japan.

The slossonae species-group is a small group, consisting of three known species found in the Holarctic Region [i.e., S. rugglesi Nicholson \& Mickel, 1950, from USA and Canada, S. slossonae Dyar \& Shannon, 1927, from USA, and S. transiens Rubtsov, 1940, from Alaska, Canada, China, Finland, Mongolia and Russia (Crosskey, 1999; Crosskey and Howard, 1997)].

$S$. rugglesi is similar to the new species in the female genitalia but differs by the following characters: in the female, the fifth maxillary palpal segment very short, nearly as long as fourth segment; in the male, the ventral plate nearly quadrate; in the pupa, the gill with eight filaments per side, and the cocoon simple, with no anterodorsal projection (Davies et al ., 1962; Stone, 1964; Adler and Currie, pers. commun.).

S. slossonae resembles this new species in the female 
genitalia but is different by having the male ventral plate nearly quadrate, the pupal gill composed of six filaments with three long stalks, the cocoon simple, and the larval postgenal cleft deep but not reaching the hypostomium (Dyar and Shannon, 1927; Stone and Snoddy, 1969; Adler and Currie, pers. commun.).

S. transiens appears to have much closer similarities to this new species by having the broad male ventral plate and the deep larval postgenal cleft reaching the hypostomium, but is easily distinguished by the following characters: the female genital fork with narrow arms, the male style with spinous basal protuberance; the pupal gill with four filaments per side, pupal head and thoracic integuments with sharp conical tubercles, and the cocoon simple (Rubtsov, 1989; Adler and Currie, pers. commun.).

\section{ACKNOWLEDGEMENTS}

We thank Dr. P. Adler, Clemson University, USA, Dr. D. Currie, Royal Ontario Museum, Canada, and Dr. D. Craig, Alberta University, Canada, for providing valuable information and references on the slossonae species-group. Thanks are due to Dr. R. W. Crosskey, The Natural History Museum, UK, for his kind suggestion on this study. Our appreciation goes to Dr. A. Kanayama, who kindly helped in the colleciton of black flies in Hokkaido, and to Dr. Y. Otsuka for his kind help in taking the photographs of the larval characters.

\section{REFERENCES}

1) Crosskey, R. W. (1969): A re-classification of the Simuli- idae (Diptera) of Africa and its islands. Bull. Br. Mus. Natur. Hist. (Entomol.) suppl. 14, 1-195

2) Crosskey, R. W. (1999): First Update to the Taxonomic and Geographical Inventory of World Blackflies (Diptera: Simuliidae). 10 pp., The Natur. Hist. Mus., London.

3) Crosskey, R. W. and Howard, T. M. (1997): A New Taxonomic and Geographical Inventory of World Blackflies (Diptera: Simuliidae). 144 pp., The Natur. Hist. Mus., London.

4) Currie, D. C. (1997): Black flies (Diptera: Simuliidae) of the Yukon, with reference to the black-fly fauna of northwestern North America. pp. 563-614. In: H. V. Danks \& J. A. Downes (eds.). Insects of the Yukon. 1034 pp., Biological Survey of Canada (Terrestrial Arthropods), Ottawa.

5) Davies, D. M., Peterson, B. V. and Wood, D. M. (1962): The black flies (Diptera: Simuliidae) of Ontario. Part I. Adult identification and distribution with descriptions of six new species. Proc. Entomol. Soc. Ont., 92, 70-154

6) Dyar, H. G. and Shannon, R. C. (1927): The north American two-winged flies of the family Simuliidae. Proc. U. S. Nat. Mus., 69, 1-54

7) Rubtsov, I. A. (1989): Blackflies (Simuliidae). Fauna of the USSR, Diptera, Volume 6, Part 6, xxviii + 1042 pp. (English translation, 2nd edition), Amerind Publishing Co., New Delhi.

8) Stone, A. (1964): Simuliidae and Thaumaleidae. Guide to the Insects of Connecticut. State Geol. \& Natur. Hist. Surv. Conn. Bull., 97, 1-126

9) Stone, A. and Snoddy, E. L. (1969): The black flies of Alabama (Diptera: Simuliidae). Auburn Univ. Agric. Exp. Stn. Bull., 390, 1-93

10) Takaoka, H. (1983): The Blackflies (Diptera: Simuliidae) of the Philippines. xi +199 pp., Japan Society for the Promotion of Science, Tokyo. 